\title{
O protagonismo discente no contexto das políticas afirmativas em educação científica
}

The students' role in the context of affirmative policies on Science Education

\author{
A. M. Santana ${ }^{1 *}$; M. C. R. Paranhos ${ }^{1}$; A. A. $\operatorname{Pagan}^{2}$ \\ ${ }^{1}$ PPGECIMA, Universidade Federal de Sergipe, CEP, São Cristóvão-SE, Brasil \\ ${ }^{l}$ Departamento de Biologia, Universidade Federal de Sergipe, CEP, São Cristóvão-SE, Brasil \\ *alynedsr@gmail.com \\ (Recebido em dia de 26 de outubro de 2016; aceito em 19 de abril de 2017)
}

\begin{abstract}
O presente artigo teve como objetivos discutir se é possível, através do conceito de singularidade, empoderar o aluno para a inovação e torna-lo protagonista da própria inclusão; Além de propor o conceito de inovação inclusiva no contexto da formação de professores de biologia e na educação científica, buscamos relacionar as duas temáticas focando no aluno e pensar a inclusão partindo dele. Neste sentido, elencamos 3 categorias visando: 1- problematizar o Ensino superior e o sistema de cotas; 2- O papel da singularidade e do protagonismo nas práticas inclusivas; e 3- Inovação Inclusiva como conceito educacional. Diante do panorama do Ensino Superior brasileiro, é notória a falta de preparo e as dificuldades enfrentadas pelos estudantes. Faz-se necessário, além das políticas afirmativas, um acompanhamento e medidas de permanência dos alunos. A inovação inclusiva pode suprir essa demanda no momento em que se observam as singularidades dos discentes, dando a eles os subsídios necessários para tornarem-se protagonistas de sua própria inclusão, propondo as mudanças e inovações que eles necessitam. Palavras-chave: Singularidades; cotas; Educação Especial;
\end{abstract}

This article aimed to discuss whether it is possible, through the concept of uniqueness, empower the student for innovation and makes it protagonist of his own inclusion; In addition to proposing the concept of inclusive innovation in the training of biology teachers and science education, we seek to link the two themes focusing on student and think the inclusion starting it. In this sense, we list three categories in order to: 1 discuss higher education and the quota system; 2 . The role of uniqueness and leadership in inclusive practices; 3- Innovation and Inclusive as an educational concept. Before the panorama of Brazilian Higher Education, it is notorious lack of preparation and the difficulties faced by students. it is necessary, in addition to affirmative action policies, monitoring and student residence measures. Inclusive innovation can meet this demand when we observe the singularities of students, giving them the necessary support to become protagonists of their own inclusion, proposing changes and innovations they need

Keywords: singularities ; quotas; Special education;

\section{INTRODUÇÃO}

A educação científica vem passando por modificações ao longo dos anos e na cultura atual "a ciência ocupa um lugar privilegiado" e cada vez mais as inovações tecnológicas, ligadas a ela, estão presentes na vida das pessoas [1]. Além disso, a ciência adquiriu um caráter de poder que faz com que as pessoas acreditem cegamente no "cientificamente comprovado" [2]. Mesmo professores de ciências, brasileiros, apresentaram imagens deturpadas do que é ciência e estão mais próximos de habituais reducionismos científicos e mais distantes de uma aprendizagem significativa das ciências [3].

Nasce então, a necessidade de que todos sejam instruídos de conceitos científicos básicos para que possam lidar com o mundo caracterizado pela compreensão das interações entre ciência, tecnologia e sociedade. Podemos possibilitar a oportunidade de construir conhecimento básico sobre ciências e como seus processos funcionam e este seria um dos aspectos da inclusão social[4]. Dar às pessoas subsídios para que construam fundamentos para entender o que acontece ao seu redor, discutindo assuntos polêmicos e participando ativamente da sociedade moderna. 
O perfil das ciências é destacado por alguns autores como conteudista e sua forma de abordagem é marcada pelas exaustivas memorizações, além da descontextualização e falta de articulação com as outras disciplinas [5]. Existem debates girando em torno da dificuldade do aprendizado de ciências e a esse respeito, o aprendizado do ensino de ciências foi comparado a aprender uma nova língua [6] e os currículos de ciências necessitam de uma revisão profunda com a participação dos alunos nessas decisões [7]. Essa dificuldade enfrentada pelos alunos para se aprender ciências se intensifica no caso de alunos que possuem deficiências sejam elas educacionais, físicas e/ou sociais.

Essa dificuldade enfrentada pelos alunos para aprender ciências se intensifica no caso daqueles que apresentam deficiências, sejam elas educacionais, físicas e/ou sociais.

A Educação Especial é responsável por acolher pessoas com necessidades educacionais especiais, e neste grupo se incluem todos os alunos que tenham dificuldades no campo da aprendizagem, seja deficiência física, sensorial, mental ou múltipla, e ainda os discentes que possuam altas habilidades, superdotação ou talentos [8].

Com a proposta da compreensão de singularidades, entendidas neste estudo como modo particular de ser, agir e pensar de cada pessoa, buscamos ampliar esse significado compreendendo que todo o aluno apresenta necessidades educacionais especiais, que podem ser identificadas em sua trajetória de vida. Acontecimentos ou características que por alguns podem ser considerados como aspecto limitante para seu desenvolvimento, sob a perspectiva da singularidade, pode ser ressignificado como ponto chave para a transformação social. Os estudantes podem identificar suas singularidades e ao tomar consciência delas, dar-lhes voz frente ao sistema de ensino padronizador, reivindicando mudanças que lhes proporcionem melhor acesso ao conhecimento.

Diante dessas colocações, o objetivo deste trabalho é relacionar os termos singularidades, inovação e inclusão como forma de delinear o ensino de ciências, no qual, o aluno é posto como o protagonista de sua inclusão. Além disso, repensamos gestão e docência para inovação discutindo a relação existente entre eles, a fim de definir a inovação inclusiva e seus principais aspectos.

Para isso, realizamos uma pesquisa de cunho teórico, na qual foram selecionados artigos em periódicos nacionais e internacionais que versavam sobre as temáticas supracitadas. As leituras serviram de base para iniciarmos a discussão trazendo o panorama atual das pesquisas realizadas no Ensino superior, pós políticas afirmativas, focando nas cotas sociais e raciais. Por fim, abordamos a singularidade e o protagonismo dos alunos como forma de inclusão, propondo, portanto, o termo Inovação Inclusiva no contexto universitário de acordo com os temas sugeridos nesse estudo.

\section{RELAÇÕES ENTRE SINGULARIDADES, INOVAÇÃO E INCLUSÃO}

Se por um lado a universidade é um ambiente de formação e construção de conhecimentos, capaz de atuar como elaboradora ou reprodutora de valores morais, éticos e construir conhecimentos científicos [9], por outro, a sociedade atual enfrenta graves problemas relacionados às aprendizagens e que esses problemas vêm se intensificando a cada dia refletindo nas licenciaturas, tanto no seu caráter institucional quanto aos currículos bem como os conteúdos abordados nos cursos de formação docente [10].

O aluno pouco preparado e motivado do ensino básico, em meio à transição da adolescência para a fase adulta, se defronta com um mundo novo. Um ambiente totalmente adverso ao que ele estava acostumado e tem de amadurecer abruptamente quanto à sua postura nos estudos.

A transição para o ensino superior implica e é concomitante com uma série de mudanças na vida do estudante, cujo impacto depende das características desenvolvimentais do próprio jovem e das exigências e apoios dos novos contextos [11].

Existem evidências de procedimentos discriminatórios atuantes nos sistemas de ensino, injuriando crianças, adolescentes, jovens e adultos negros, causando a sua evasão e fracasso, isso vai se refletir no baixo número de negros que chegam ao ensino superior, cerca de $10 \%$ da população universitária do país [12]. Porém, a exclusão de determinados grupos, que se espalhou como epidemia no início do século, agora está, por parte de políticas públicas, passando por uma fase de diversas tentativas de eliminação [13]. 
Criaram-se projetos de luta contra a exclusão nos mais diversos domínios sociais: combate à pobreza, à exclusão social, à exclusão na justiça e na saúde, enfim, contra a exclusão social vista como um todo [13].

Um exemplo dessa tentativa de compensação é a criação e implantação de políticas afirmativas, que no caso das universidades visa, principalmente, a reserva de vagas em universidades públicas, tanto para alunos negros e pardos, quanto para os de classe econômica baixa. Além de garantir também vagas e condições para que deficientes possam cursar o ensino superior.

Em 2004, foi implantada a expansão orgânica das universidades brasileiras com o intuito de universalizar o ensino superior. Em agosto de 2012 foi sancionada a Lei $n^{\circ}$ 12.711/2012, garantindo a reserva de $50 \%$ das matrículas por curso e turno nas 59 universidades federais e 38 institutos federais de educação, ciência e tecnologia a alunos oriundos integralmente do ensino médio público, em cursos regulares ou da educação de jovens e adultos. E dessas vagas, uma porcentagem de acordo com a quantidade de negros, pardos e indígenas na localidade da universidade pretendida, são assegurados pela mesma lei [14].

As políticas afirmativas são importantes para o avanço da sociedade em geral, foi a partir delas que determinados grupos da sociedade puderam ter voz e garantir direitos iguais aos grupos mais favorecidos. Nas universidades, as reservas de vagas para alunos negros, deficientes e de classe social baixa deram oportunidades a esses alunos de cursar o nível superior e mudar estigmas sociais. Mas, assim como no caso dos deficientes, pouco se tem feito para garantir a permanência dos cotistas nas universidades. Exceto os programas de auxílio financeiro, os alunos não recebem suporte emocional para enfrentar os desafios do mundo acadêmico.

Nesse sentido buscamos medidas que realmente efetivem a inclusão dos alunos no ensino superior. Para isto pesquisamos os conceitos de singularidade e protagonismo relacionando-os na perspectiva inclusiva.

Dois conceitos muito presentes nos trabalhos de inclusão, singularidade e protagonismo remetem a dar voz ao sujeito. No primeiro, entendemos que cada pessoa é única, possui características somente suas dentro de seu modo de pensar, ser e agir. Cada aluno tem seu modo particular de aprender, refletido em sua cultura e experiência de vida. Essas características particulares de ser são entendidas aqui como singularidades.

No ensino tradicional, o aluno é tratado de forma coletiva e precisa reproduzir, literalmente, o que lhe foi ensinado. Assume-se que o processo de aprendizagem siga uma evolução linear, única e a-histórica, em todos os sujeitos como se todos tivessem as mesmas fases de desenvolvimento afetivo, cognitivo, social e sexual [15]. Como se fosse algo comum a todas as pessoas e culturas, persistindo a pedagogia baseada na concepção de que o sujeito se desenvolve naturalmente passando por etapas e processos [15].

No início de sua trajetória escolar, o aluno transporta para a escola além da influência cultural de sua comunidade, algo muito profundo, a sua singularidade. Com aspectos próprios, o aluno se lançará no processo da aprendizagem escolar, completando essa trajetória e prosseguindo a sua construção enquanto pessoa nas novas e importantes experiências no espaço social [16].

A inclusão escolar carece da elaboração de propostas adequadas para garantir a participação social desses sujeitos, levando em conta suas especificidades, pautada pela constante busca da valorização da diversidade humana, e assumindo o compromisso com o atendimento pedagógico necessário para êxito acadêmico de todos, independentemente de suas singularidades [17].

O outro conceito presente nos trabalhos de inclusão é o protagonismo. Abordado em diversos trabalhos em ciências sociais, o protagonismo geralmente está relacionado a minorias. Seu conceito gera controvérsia no meio sociológico e muitos autores confundem participação e protagonismo [18].

E foi no contexto da participação dos alunos nos processos de gestão da escola, o qual na década de 90 foi incentivado e valorizado pelo governo através de documentos oficiais, surgiu o termo protagonismo [19]. O objetivo é propiciar aos indivíduos sua independência de atitudes e escolhas e fazer com que ele próprio tome as iniciativas para mudar sua realidade. Acreditamos que ao dar oportunidade para aluno pensar sozinho fará ele ser mais independente e crítico quanto ao mundo que o rodeia. 
Assim, para uma efetiva inclusão, defendemos que se observem primeiro as singularidades dos alunos, e depois se incentive a tomada de decisão deles, fazendo com que eles reflitam sobre suas dificuldades e pensem modos de melhorar sua participação no meio acadêmico. Nesse sentido propomos o termo Inovação Inclusiva no contexto educacional.

Para propor o conceito "Inovação Inclusiva" precisamos ter bem ancorados os significados das palavras inovação e inclusão. Os dois temas geralmente são alvos de debates e geralmente estão interligados mesmo sem, de fato, serem correlacionados.

A inovação é um tema atual e de diversas áreas. Na educação, muitas vezes, é vista de forma equivocada. Ao contrário do que muitos acreditam em tecnologia não é um conjunto de maquinas e equipamentos eletrônicos, mas sim um meio, uma solução para uma determinada necessidade ou problema [20]. É notória a quantidade de recursos tecnológicos visíveis à sociedade, mas esses avanços pouco entraram nas salas de aula [21]. Geralmente o que se pensa ser inovação na educação está somente ligado a metodologias diferenciadas utilizadas nas aulas.

É importante também que essas inovações não sejam pensadas somente pelos professores ou gestores, é necessário que o aluno seja incentivado a pensar inovações para resolver as questões que afetam o desempenho deles próprios e dos colegas à fim de incluir-se no meio em que estão inseridos.

Focando na inclusão aberta e interativa [22], a Inclusão escolar está intrinsecamente ligada ao respeito às singularidades apresentadas pelos alunos, reconhecendo-os como indivíduos que têm particularidades que necessitam ser ponderadas na elaboração de iniciativas pedagógicas que objetivem garantir o desenvolvimento cognitivo desses sujeitos [17].

Diante desse panorama, Inovação Inclusiva para a educação seria buscar analisar cada indivíduo e motivar que ele se auto avalie também. Uma vez que o indivíduo se conhece ele poderá identificar seus pontos fortes e fracos, e buscar alternativas para solucionar eventuais barreiras para seu sucesso no desempenhar das funções. Somente a pessoa que passa por determinada situação saberá o que pode ser mudado para que seu desempenho seja favorecido, e uma vez emancipado ele poderá gerar mudanças não só para ele, mas para outros que eventualmente sofram com os mesmos problemas.

O termo Inovação inclusiva é entendido aqui como uma forma de capacitar os alunos, observando suas singularidades, para que eles, emancipados, tornem-se protagonistas do seu conhecimento e busquem formas de se incluir no contexto universitário, assim inovando e participando de forma efetiva deste contexto.

\section{CONSIDERAÇÕES}

Diante do panorama do Ensino Superior brasileiro, é notória a falta de preparo e as dificuldades enfrentadas pelos estudantes. Como solução para a exclusão de alguns grupos sociais ao direito da educação superior, foram criadas diversas medidas compensatórias, políticas afirmativas que entre outras coisas designa cotas para alunos deficientes, de classe econômica baixa e negros, pardos e índios. Porém faz-se necessário, além dessas políticas afirmativas, um acompanhamento e medidas que visem a permanência dos alunos, medidas que vão além do incentivo econômico, formas de inserir o aluno no mundo da universidade. A inovação inclusiva pode suprir essa demanda no momento em que se observam as singularidades dos discentes, dando a eles os subsídios necessários para tornarem-se protagonistas de sua própria inclusão, propondo as mudanças e inovações que eles necessitam.

Concluímos por fim que é válida a discussão em torno do conceito de singularidade, empoderando o aluno para a inovação e tornando-o protagonista da própria inclusão; propomos neste artigo o conceito de inovação inclusiva no contexto da formação de professores de biologia e na educação científica, e relacionamos as duas temáticas focando no aluno, pensando a inclusão partindo dele.

\section{AGRADECIMENTOS}

CNPq, Programa de Pós-Graduação em Ensino de Ciências e Matemática (PPGECIMA). 


\section{REFERÊNCIAS BIBLIOGRÁFICAS}

1. Scheid NMJ, Ferrari N, Delizoicov D. Concepções sobre a natureza da ciência num curso de ciências biológicas: imagens que dificultam a educação científica. In: Investigações em Ensino de Ciências. 2007;12(2):157-181.

2. Vilela TM, Junior AD. "O cientificamente comprovado": reflexões sobre a autoridade da Ciência na sociedade contemporânea. In: Revista Faz Ciência. 2005;7(1):27-40.

3. Gil Pérez D, Montoro IF, Alís JC, Cachapuz A, Praia J. Para uma imagem não deformada do trabalho científico. In: Ciência \& Educação. 2001;7(2):125-153.

4. Moreira, I de C. A inclusão social e a popularização da ciência e tecnologia no Brasil. In: Inclusão Social. 2006;1(2):1-6.

5. Teixeira PMM. A educação científica sob a perspectiva da pedagogia histórico-crítica e do Movimento C.T.S. no ensino de ciências. In: Ciência \& Educação. 2003;9(2):177-190.

6. Chassot AI. A Ciência é masculina? É, sim senhora!. 5. ed. São Leopoldo, RS: Unisinos; 2003. 134 p.

7. Krasilchik M. Caminhos do Ensino de Ciências no Brasil. In: Enfoque: qual é a questão. Brasília. 1992;11(55):3-8

8. Castanho DM, Freitas SN. Inclusão e prática docente no ensino superior. In: Revista Educação Especial. 2006;27(1):93-99.

9. Santos RA, Lima SR, Santana JRM, Lima MB. Identidades e inclusão social no ensino superior: Um estudo na Universidade Federal de Sergipe. In: IV Colóquio Internacional Educação e Contemporaneidade, São Cristóvão- Sergipe. 2010.

10. Gatti BA. Formação de Professores no Brasil: Características e Problemas. In: Educ. Soc., Campinas. 2010;31(113):1355-1379.

11. Santos L, Almeida LS. Vivências académicas e rendimento escolar: Estudo com alunos universitários do 1. ${ }^{\circ}$ ano. In: Análise Psicológica. 2001;2(1):205-217.

12. Brito MPR. Políticas De Ações Afirmativas: Análise Do Sistema De Cotas Da Uerj Através Dos Grupos Focais. (Monografia) Universidade do Estado do Rio de Janeiro, Faculdade de Formação de Professores, São Gonçalo; 2011.73 p.

13. Rodrigues D. Inclusão e educação: Doze olhares sobre a educação inclusiva. São Paulo: Summus; 2006. $120 \mathrm{p}$.

14. Brasil. Ministério da Educação. Disponível em <http://portal.mec.gov.br/cotas/legislacao.html> Acesso em 27 Abr. 2015.

15. Buchvit PA. Do Significado ao Significante: A Singularidade do Saber. In: Revista Perspectivas online. 2005;5(1):194-198

16. Tacca MCVR, González-Rey FL. Produção de Sentido Subjetivo: As Singularidades dos Alunos no Processo de Aprender. In: Psicologia, Ciência e profissão. 2008;28(1):138-161.

17. Moscardini SF, Sigolo SRRL. Inclusão Escolar do Aluno com Deficiência Intelectual: Práticas Pedagógicas no Ensino Comum e no Atendimento Educacional Especializado. In: XVI ENDIPE Encontro Nacional de Didática e Práticas de Ensino - UNICAMP - Campinas - 2012.

18. Ferretti CJ, Zibas DML, Tartuce GLBP. Protagonismo juvenil na literatura especializada e na reforma do ensino médio. In: Cadernos de Pesquisa. 2004;34(122):411-423.

19. Ferretti CJ. A inovação na perspectiva pedagógica. In: Walter E. Garcia (Org) Inovação Educacional no Brasil - Problemas e Perspectivas. Editora Autores Associados; 1995. 90 p.

20. Rodrigues LMBC. Tecnologia Assistiva no processo de inclusão da pessoa com deficiência na rede pública de ensino. (Dissertação). Universidade Estadual Paulista"Julio de Mesquita Filho" - UNESP. Bauru; 2013. 127 p.

21. Siqueira MRP. Professores de Física em contexto de inovação curricular: Saberes docentes e superação de obstáculos didáticos no Ensino de Física Moderna e Contemporânea. (Tese). Universidade de São Paulo. São Paulo; 2012. 202 p.

22. Candau VM. Multiculturalismo e educação: desafios para aprática pedagógica. In: Moreira AF (ORGs). Multiculturalismo: Diferenças culturais e práticas pedagógicas. 2a Edição. Petrópolis- RJ: Editora Vozes; 2009. 245 p. 